\title{
Corrigendum: Pre-test metyrapone impairs memory recall in fear conditioning tasks: lack of interaction with $\beta$-adrenergic activity
}

\section{OPEN ACCESS}

Edited and reviewed by: Francesca Cirulli,

Istituto Superiore di Sanità, Italy

*Correspondence:

Deborah Suchecki,

deborah.suchecki@gmail.com

Received: 07 April 2015 Accepted: 20 April 2015

Published: 13 May 2015

Citation:

Careaga MBL, Tiba PA, Ota SM and Suchecki D (2015) Corrigendum: Pre-test metyrapone impairs memory recall in fear conditioning tasks: lack of interaction with $\beta$-adrenergic activity.

Front. Behav. Neurosci. 9:123.

doi: 10.3389/fnbeh.2015.00123

\begin{abstract}
Mariella B. L. Careaga ${ }^{1}$, Paula A. Tiba ${ }^{2}$, Simone M. Ota ${ }^{1}$ and Deborah Suchecki ${ }^{1 *}$
' Departamento de Psicobiologia, Escola Paulista de Medicina, Neurobiology of Stress and Stress-Related Disorders, Universidade Federal de São Paulo, São Paulo, Brazil, ${ }^{2}$ Centro de Matemática, Computação e Cognição, Universidade Federal do ABC, São Paulo, Brazil
\end{abstract}

Keywords: memory, metyrapone, propranolol, fear conditioning, retrieval

\section{A Corrigendum on}

Pre-test metyrapone impairs memory recall in fear conditioning tasks: lack of interaction with $\beta$-adrenergic activity

by Careaga, M. B. L., Tiba, P. A., Ota, S. M., and Suchecki, D. (2015). Front. Behav. Neurosci. 9:51. doi: 10.3389/fnbeh.2015.00051

Grant information was missing on the original publication. The updated acknowledgment section is provided below.

\section{Acknowledgments}

The authors would like to thank Marcos Vinicius Bunscheit for his technical contribution. This work was supported by Associação Fundo de Incentivo à Pesquisa (AFIP) and Coordenação de Apoio a Pessoal de Nível Superior (CAPES). DS is the recipient of a research fellowship from Conselho Nacional de Desenvolvimento Científico e Tecnológico (CNPq). MC is the recipient of a graduate fellowship from Fundação de Amparo à Pesquisa do Estado de São Paulo (FAPESP 2011/16977-8). Payment of this publication was made possible by a grant from FAPESP (2015/02076-0).

Conflict of Interest Statement: The authors declare that the research was conducted in the absence of any commercial or financial relationships that could be construed as a potential conflict of interest.

Copyright (๑) 2015 Careaga, Tiba, Ota and Suchecki. This is an open-access article distributed under the terms of the Creative Commons Attribution License (CC BY). The use, distribution or reproduction in other forums is permitted, provided the original author(s) or licensor are credited and that the original publication in this journal is cited, in accordance with accepted academic practice. No use, distribution or reproduction is permitted which does not comply with these terms. 